\title{
STABILITY THEORY OF FUZZY DIFFERENTIAL EQUATIONS VIA DIFFERENTIAL INEQUALITIES
}

\author{
V. LAKSHMIKANTHAM AND S. G. LEELA
}

\begin{abstract}
Lyapunov theory of stability is developed for fuzzy differential equations employing suitable theory of differential inequalities. Method of perturbing Lyapunov function is utilized which provides weaker assumptions for discussing stability theory.
\end{abstract}

Mathematics subject classification (1991): 34D20, 34A40, 34L99.

Key words and phrases: Fuzzy differential equations, differential inequalities, stability theory.

\section{REFERENCES}

[1] Driankov, D., Hellendorm, H. And Reinfrank, M., An introduction to fuzzy control, Springer Verlag, Berlin, 1996.

[2] DubOIS, D AND Prade, H., Towards fuzzy differential calculus, Part I, Fuzzy Sets and Systems 8 (1982), 1-17.

[3] , Towards fuzzy differential calculus, Part II, Fuzzy Sets and Systems 8 (105-116).

[4] Dubois, D And Prade, H., Towards fuzzy differential calculus, Part III, Fuzzy Sets and Systems 8 (1982), 225-234.

[5] Friedman, M., Ming, M. AND KAndel, A., On the validity onf the Peano's theorem for fuzzy differential equations, Fuzzy Sets and Systems 86 (1997), 331-334.

[6] KaleVA, O., Fuzzy differential equations, Fuzzy Sets and Systems 25 (1987), 301-317.

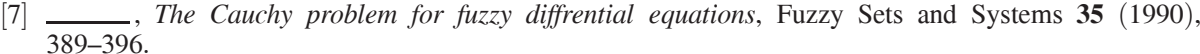

[8] Kloeden, P. E., Remarks on Peano-like theorems for fuzzy differential equations, Fuzzy Sets and Systems 44 (1991), 161-163.

[9] Lakshmikantham, V. And Leela, S., Differential and integral inequalities, Vol I, Academic Press, New York, 1969.

[10] _ Nonlinear differerntial equations in abstract spaces, Pergamon Press, Oxford, 1981.

[11] On perturbing Lyapunov functions, Math. System Theory 10 (1976), 85-90.

[12] LaKshmikantham, V. AND MOHAPATRA R. N., Basic properties of soltions of fuzzy differential equations (to appear).

[13] NiETO, J. J, The Cauchy problem for fuzzy diferential equations, Fuzzy Sets and Systems (to appear).

[14] NovaK, V., Fuzzy Sets and Their Applications, Adam Hilger, Bristol, 1988. 